\title{
O Papel das Rendas Não-agrícolas para Redução da Pobreza e Concentração na Região Sul
}

\section{The Role of Non-agricultural Income in Reducing Rural Poverty and Inequality in South Region}

\author{
João Ricardo Ferreira de Lima ${ }^{1}$ \\ Carlos Alberto Piacenti ${ }^{2}$
}

\begin{abstract}
Resumo: Na região Sul, pode-se considerar que a maior parte dos produtores têm mais acesso a tecnologia, estão integrados aos complexos agroindustriais e percebem renda média familiar mais elevada do que os produtores de outras regiões do país. Mesmo assim, a busca por diversificação da renda, principalmente de fonte não-agrícola, parece ser uma importante estratégia das famílias para elevar a renda familiar. Este artigo analisa o papel das rendas não-agrícolas na redução da pobreza rural e na concentração de renda na região Sul. Utilizam-se os dados da PNAD/IBGE para o ano de 2005. O modelo teórico está relacionado à oferta de mão-de-obra rural, focando a possibilidade dos membros da família se engajar (ou não) em múltiplas fontes de emprego. O modelo econométrico é o Tobit II, estimado por máxima pseudo-verossimilhança, sendo feitas simulações nas rendas das famílias buscando estimar a renda média, o nível de pobreza e o de concentração, na presença e na ausência das rendas não-agrícolas. Os resultados obtidos demonstram, com relação à concentração, que a renda não-agrícola contribui para diminuição da concentração, reduzindo os índices de Gini e Theil. Sobre a pobreza rural, utilizando os índices FGT, tanto no caso da proporção de pobres (P0), quanto no hiato da pobreza (P1) e severidade da pobreza (P2), observa-se que as rendas não-agrícolas contribuem para redução da pobreza. Com estas informações, considera-se importante pensar em políticas públicas que estimulem a pluriatividade e/ou o acesso a rendas não-agrícolas.
\end{abstract}

Palavras-chave: Renda não-agrícola. Desigualdade. Pobreza.

$1 \quad$ D.Sc. em Economia Aplicada - DER/UFV. Prof. Adjunto do Departamento de Ciências Fundamentais e Sociais do Centro de Ciências Agrárias da UFPB - Areia. E-mail: jricardo@ cca.ufpb.br

2 D.Sc. em Economia Aplicada pela Universidade Federal de Viçosa (UFV). Professor Assistente do Colegiado de Economia da UNIOESTE/ Campus de Toledo. Pesquisador do Grupo de Estudo e Pesquisa em Agronegócio e Desenvolvimento Regional (GEPEC).E-mail: piacenti8@ yahoo.com.br

LIMA, J. R. F.; PIACENTI, C. A. O papel das rendas não-agrícolas para redução da pobreza... 
Abstract: In South region can be considered that the most part of farmers has more access to technology, are integrated to the agroindustries complex and their average household income are higher then the others regions farmers. Even thus, the seek to diversificate the rent, mainly of non-agricultural source, seems to be an important estrategy to increase the household income. This article analysis the role of non-agricultural income in reducing rural poverty and inequality in South region. The used data are the PNAD/IBGE microdata of 2005. The theoretical framework is related to rural labour supply, centering in the possibility of the households members to engage (or not) in multiple job offers. The econometric model is Tobit II, estimated by maximizing the log-pseudolikelihood function, being made simulation in household income to estimate the average income, the poverty and inequality level, with and without non-agricultural income. Results show that, with regard to inequality, the nonagricultural income contributes in reducing the inequality, decreasing the Gini and Theil indexes. With regard to rural poverty, using the FGT index, as much for headcount ratio (P0), how much for poverty-gap (P1) and square povertygap (P2), is observed that the non-agricultural income contribute to reducing poverty. With this information, it's considered important to think public policies that estimulate the pluriactivity and/or the access to non-agricultural income.

Keywords: Non-agricultural income. Inequality. Poverty.

JEL Classification: J22; R23; C34.

\section{Introdução}

O termo pluriatividade surge no cenário internacional na década de 70 do século XX, em referência à combinação do exercício de atividades agrícolas e não-agrícolas pelos membros de uma mesma família. As familias se tornavam pluriativas buscando diversificar suas fontes de renda para conseguir melhorar a condição de vida e se manter no local de origem (CARNEIRO, 2005). No Brasil, pesquisas relacionadas ao tema aparecem na década de 90, principalmente, nos trabalhos do projeto Rurbano do IE/UNICAMP (GRAZIANO DA SILVA, 1999).

Atualmente, parece claro que, no Brasil, a pluriatividade é uma estratégia dos agricultores para aumentar a renda familiar. A diferença entre o processo dos países desenvolvidos e do que ocorre nos países em desenvolvimento é que, nos primeiros, se têm forte apoio de políticas públicas, como a PAC (Política Agrícola Comum) na Europa (NASCIMENTO, 2005).

Especificamente para a região Sul, diversos trabalhos (SCHNEIDER, 2003, 2004; MATTEI, 1999; ou SOUZA, 2000) demonstraram que a pluriatividade é importante para os agricultores familiares, mesmo aqueles 
modernizados e integrados aos Complexos Agroindustriais, pois contribui para elevação da renda, comparativamente aos exclusivamente agrícolas. Por outro lado, segundo Nascimento (2005), a pluriatividade cresce mais em regiões pobres, como a Nordeste e não apresenta taxa geométrica de crescimento estatisticamente significativa para nenhum tipo de família da região Sul.

Não adentrando no debate sobre o não-crescimento da pluriatividade na região Sul, este trabalho busca analisar a importância da pluriatividade e das rendas não-agrícolas para redução da pobreza e concentração no meio rural da região. Especificamente, busca-se comparar, através de simulações nas rendas das familias, o impacto do não-agrícola para as famílias exclusivamente agrícolas e para as pluriativas. Além disso, pretende-se identificar efeitos positivos da renda não-agrícola para a atividade agropecuária. A hipótese a ser testada é que a pluriatividade reduz a pobreza rural e a concentração na região.

\section{Referencial Teórico}

O referencial teórico utilizado neste trabalho está relacionado à oferta de mão-de-obra rural, focando a possibilidade das famílias poderem se engajar apenas em atividades agrícolas ou serem pluriativas. Segundo essa abordagem, a família compara as opções de trabalho e aloca seu tempo total disponível de forma a maximizar sua função de utilidade. Busca-se, assim, modelar o domicílio de forma a entender as decisões da família sobre consumo, produção e a alocação de tempo (LEE, 1998).

Como a unidade analítica utilizada na pesquisa é a família, é necessário um modelo que capte a interdependência das decisões de oferta de trabalho. A decisão de um membro da família de participar em atividades não-agrícolas deve ter uma relação de interdependência com a decisão de outro membro. Segundo Lee (1998), analisar a decisão familiar de oferta de trabalho envolve a questão de como modelar a maneira que os membros tomam suas decisões econômicas. Basicamente, existem três grupos de modelos, ${ }^{3}$ mas por facilidade de interpretação esta pesquisa utiliza o modelo de "utilidade conjunta" (joint utility).

Segundo Lee (1998), a abordagem da utilidade conjunta assume que os membros da família maximizam uma função de utilidade, a qual é comum a todos. Essa função de utilidade possui os atributos e o comportamento econômico dos membros com argumentos separados (porém

3 Os outros dois modelos são o da "família tradicional" e o de "barganha". Para maiores informações, vide Lee (1998).

LIMA, J. R. F.; PIACENTI, C. A. O papel das rendas não-agrícolas para redução da pobreza... 
agregáveis), assim como as propriedades usuais da função de utilidade da teoria do consumidor individual. É usada para modelar domicílios parcialmente integrados aos mercados. A família, internamente, decide o que consumir e produzir, bem como quanto ofertar de trabalho nas atividades agrícolas e não-agrícolas. Uma hipótese importante do modelo é a total cooperação entre os membros da família. Para facilidade de exposição, é apresentado o caso de uma família composta de duas pessoas e que pode ser estendido para o caso de uma família com $n$ componentes. A família, então, busca maximizar a seguinte função de utilidade,

$$
\max _{T_{\mathrm{d} 1}, T_{\mathrm{d} 2}, C, T_{\text {agr } 1}, T_{\text {agr } 2}, T_{\text {nag1 }}, T_{\text {nag2 }},} U\left(T_{\mathrm{d} 1}, T_{\mathrm{d} 2}, C ; J\right)
$$

sujeito a

$$
\begin{aligned}
& C=f\left(p ; T_{\text {agr } 1}, T_{\text {agr } 2} ; H, Z_{\text {agr }}\right)+g\left(T_{\text {nag } 1}, T_{\text {nag } 2} ; H, Z_{\text {nag }}\right)+R N T \\
& T_{\mathrm{i}}=T_{\text {di }}+T_{\text {agri }}+T_{\text {nagi, }} \text { com } i=1,2 \\
& T_{\text {agri }}, T_{\text {nagi }} \geq 0, \operatorname{com} i=1,2
\end{aligned}
$$

onde,

$T_{\mathrm{d}}=$ tempo alocado nas atividades do domicílio, envolvendo os cuidados com os membros familiares e atividades afins, podendo também ser considerado como lazer;

$C=$ consumo de bens;

$J=$ características da família que afetam suas preferências;

$f=$ indica que o consumo é uma função $f$ da renda agrícola;

$g=$ indica que o consumo é uma função g da renda não-agrícola;

$p=$ vetor de preços dos produtos agrícolas e insumos, menos o trabalho no próprio domicílio;

$T_{\text {agr }}=$ tempo de trabalho em atividades agrícolas na propriedade;

$Z_{\text {agr }}=$ insumos fixo da propriedade;

$T_{\text {nag }}=$ tempo de trabalho em atividades não-agrícolas dentro ou fora da propriedade;

$H=$ Capital Humano que influencia no nível de renda agrícola e nãoagrícola;

$Z_{\text {nag }}=$ Outras variáveis que influenciam o nível salarial;

$R N T$ = Renda do "não-trabalho" ou transferências (aposentadorias, pensões, bolsas do governo, auxílio enviado por um parente que migrou etc.); $T_{\mathrm{i}}=$ Trabalho total;

$i=1$ ou 2 , se refere ao membro da família. Ex.: marido e a esposa. 
A utilidade da família é determinada pelo tempo gasto com as atividades do domicílio/lazer $\left(T_{\mathrm{d}}\right)$ e com o consumo de bens ( $C$ ). É permitido que a função de utilidade varie de acordo com as características das famílias (J). Para maximizar sua função, a família se defronta basicamente com duas restrições: a) orçamentária, ou seja, o nível de consumo depende da soma das rendas agrícola, não-agrícola e de transferências; b) temporal, ou seja, existe um montante fixo de tempo, a qual deve se alocado em atividades agrícolas, não-agrícolas e lazer. O modelo assume ainda que tanto o tempo de trabalho agrícola quanto o não-agrícola (ou ambos) pode ser zero. ${ }^{4}$ Como na maximização deste problema pode-se encontrar uma solução interior ( $T_{\text {agr }}>0$ e $T_{\text {nag }}>0$ ), mas também uma de canto (quando $T_{\text {agr }}=0$ ou $T_{\text {nag }}=0$ ou ambas), para solução do Lagrangiano é utilizado o método de Kuhn-Tucker. Sumarizando as funções de participação no mercado de trabalho $\left(L_{\mathrm{i}}^{-}\right)$, tem-se:

a) $T_{\text {nag }}=0$, famílias exclusivamente agrícolas.

$L_{\mathrm{i}}^{-}\left(H, Z_{\text {nag }}, Z_{\text {agr }}, p, T, R N T, J\right) \equiv g_{\mathrm{i}}\left(H, Z_{\text {nag }}\right)-W_{\text {iagr }}\left(H, Z_{\text {agr }}, p, T, R N T, J\right) \leq 0$

b) $T_{\text {agr }} T_{\text {nag }}>0$, famílias pluriativas.

$L_{\mathrm{i}}^{-}\left(H, Z_{\text {nag }}, Z_{\text {agr }}, p, T, R N T, J\right) \equiv g_{\mathrm{i}}\left(H, Z_{\text {nag }}\right)-W_{\text {iagr }}\left(H, Z_{\text {agr }}, p, T, R N T, J\right)>0$

$\mathrm{e}$

$L_{\mathrm{i}}^{-}\left(H, Z_{\text {nag }}, Z_{\text {agr }}, p, T, R N T, J\right) \equiv f_{\mathrm{i}}\left(H, Z_{\text {agr }}, p, T, R N T, J\right)-W_{\text {nag }}\left(H, Z_{\text {nag }}\right)>0$

Seguindo o raciocínio semelhante ao desenvolvido por Andrade (2003), se for definido " $\delta$ " como a diferença entre $g_{\mathrm{i}}-W_{\text {iagr }}$ e entre $f_{\mathrm{i}}-W_{\text {nag, }}$, pode-se argumentar que uma elevação nas variáveis que aumentam $g_{i}$ e $f_{\text {i }}$ ou reduz $W_{\text {iagr }}$ ou $W_{\text {nag }}$ contribuem para acrescer " $\delta$ ". Assim, para todos os tipos de família se espera que as variáveis relacionadas com capital humano possuam sinal positivo e que exerçam influência na decisão de participar do mercado de trabalho na mesma direção de $g_{\mathrm{i}}$ e $f_{\mathrm{i}}$ e na direção contrária de $W_{\text {iagr }}$ e $W_{\text {nag }}$. Adicionalmente, os impactos das variáveis $p, T$ e $J$ na decisão de participação ocorrem sempre na direção contrária de $W_{\text {iagr }}$ Para as famílias em que $T_{\text {agr }}$ é positivo, outras variáveis que afetam o mercado de trabalho não-agrícola $\left(Z_{\text {nag }}\right)$ possuem sinal positivo e vão à mesma direção de $g_{\mathrm{i}}$. Entretanto, $\operatorname{com} Z_{\mathrm{agr}}$ ocorre o inverso. Por outro lado, nas famílias em que $T_{\text {nag }}$ é positivo, são as outras variáveis que afetam o mercado de trabalho agrícola $\left(Z_{\text {agr }}\right)$ que possuem sinal positivo e seguem a mesma direção de $f_{\mathrm{i}}$.

4 Esta adaptação é importante, haja vista que a família pode se dedicar exclusivamente as atividades agrícolas ( $T_{\mathrm{agr}}>0$ e $\left.T_{\text {nag }}=0\right)$, ou exclusivamente a atividades não-agrícolas $\left(T_{\mathrm{agr}}=0\right.$ e $T_{\text {nag }}>0$ ), ou ainda ser pluriativa ( $T_{\text {agr }}>0$ e $T_{\text {nag }}>0$ ) ou não-ocupada, vivendo exclusivamente de transferências $\left(T_{\mathrm{agr}}=0\right.$ e $T_{\mathrm{nag}}=0$ ). Neste trabalho, restringe-se para os casos em que as famílias são exclusivamente agrícolas ou pluriativas.

LIMA, J. R. F.; PIACENTI, C. A. O papel das rendas não-agrícolas para redução da pobreza... 


\section{Metodologia}

\subsection{Determinantes da Escolha de Alternativas de Ocupação}

Duas equações são necessárias para atingir os objetivos do trabalho: uma que define a decisão da família de ser exclusivamente agrícola ou pluriativa e outra, que estima a renda média desses dois tipos de "populações". Em casos desse tipo, as estimações podem ser realizadas utilizando o procedimento de Heckman (1979), estimando um Probit com toda amostra, obtendo os valores da razão inversa de Mills e a utilizando como um dos regressores na equação que descreve a renda média.

Para estimar a equação de decisão das famílias, considera-se o modelo:

$$
P_{\mathrm{i}}^{*}=Z_{\mathrm{i}}^{\prime} \alpha+\varepsilon_{\mathrm{i}}
$$

na qual $Z_{\mathrm{i}}$ é um vetor de variáveis que explicam a decisão; $\alpha$ é o vetor de coeficientes a serem estimados e; $\varepsilon_{i}$ é o termo de erro aleatório com distribuição normal. $P_{\mathrm{i}}^{*}$ é uma variável latente, o que se observa é $P$ tal que

$$
\begin{aligned}
& P_{\mathrm{i}}=1 \text { se } P_{\mathrm{i}}^{*}>0 \text { Família é pluriativa } \\
& P_{\mathrm{i}}=0 \text { se } P_{\mathrm{i}}^{*}=0 \text { Família é exclusivamente agrícola }
\end{aligned}
$$

Com relação à renda, a equação a ser estimada é,

$$
\left(\left.\log W_{\mathrm{oi}}\right|_{P_{\mathrm{i}}}\right)=X_{\mathrm{i}}^{\prime} \beta+\gamma_{0} \lambda_{\mathrm{i}}+v_{\mathrm{i}}
$$

na qual $\left.\log W_{\mathrm{oi}}\right|_{P_{1}}$ é o logaritmo da renda condicional dos i indivíduos, seguindo o modelo de Mincer (HECKMAN et al., 2005); $X_{\mathrm{i}}$ é um vetor de variáveis que explicam a renda e que normalmente é um subconjunto de

$$
Z_{\mathrm{i}} ; \lambda_{\mathrm{i}}=\frac{\phi\left(\frac{Z_{\mathrm{i}} \alpha}{\sigma_{\mathrm{u}}}\right)}{\Phi\left(\frac{Z_{\mathrm{i}} \alpha}{\sigma_{\mathrm{u}}}\right)}
$$

é a razão inversa de Mills. Essa mensura o valor esperado da contribuição das características não observadas, na decisão dos residentes do domicílio se ocupar em atividades não-agrícolas, condicionado à participação observada (DE JANVRY et al., 2005); e $v_{\mathrm{i}}$ é o termo de erro aleatório.

\subsection{Efeitos da renda não-agrícola sobre a pobreza e a concentração}

O método utilizado a seguir é o de estimar a renda esperada da família, em cada fonte (zero e 1), para os dois grupos de populações, 
semelhante ao encontrado em De Janvry et al. (2005) e Zhu e Luo (2006). O objetivo é comparar a distribuição observada da renda total dos domicílios com outra, simulada, sem as atividades não-agrícolas. Os resultados da regressão para a fonte zero são utilizados para prever qual seria a renda média das famílias pluriativas, caso fossem exclusivamente agrícolas $\left(\left.E \hat{W}_{0}\right|_{P=1}\right)$. Por outro lado, os resultados para a fonte 1 servem para prever a renda média das famílias agrícolas, se fossem pluriativas.

Inicialmente, para exemplificar a forma de simular as rendas, considera-se $W_{0 \mathrm{i}}$ como a renda de cada família "i" que participa apenas de atividades agrícolas. ${ }^{5}$ Sabe-se que

$$
W_{0 \mathrm{i}}=E\left(\log W_{0 \mathrm{i}} \mid P_{\mathrm{i}}\right)+v_{0 \mathrm{i}}=X_{i}^{\prime} \beta+\gamma_{0} \lambda_{i}+v_{0 i}
$$

em que $\lambda$ é a razão inversa de Mills; $E\left(\log W_{0 \mathrm{i}} \mid P_{\mathrm{j}}\right)$ é o valor esperado da renda condicionado as características observadas pelas famílias e estas serem exclusivamente agrícolas; e $v_{0 \mathrm{i}}$ se refere as características que afetam a renda mas que não são observadas. O interesse é prever a renda de cada familia "i”, se fosse exclusivamente agrícola. Para as famílias agrícolas, essa é a sua renda observada. Para as famílias pluriativas, essa é a renda prevista que perceberiam caso se dedicassem apenas as atividades agrícolas. Esta previsão requer que $\llbracket E\left(v \rrbracket_{0_{\mathrm{i}}} \mid P_{\mathrm{i}}\right)=0$ e var $\llbracket\left(v \rrbracket_{0 \mathrm{i}} \mid P_{\mathrm{j}}\right)=\sigma_{0}^{2}$.

Utilizando os parâmetros estimados, pode-se prever a renda $W_{\text {oi }}$ para todas as "i" famílias (incluindo agrícolas e pluriativos). Para prever o valor esperado condicionado da renda $\left(E\left(\log \llbracket W_{\downarrow} 0 \mathrm{i} \rrbracket \mid P_{\downarrow} \mathrm{i}\right)=X_{\downarrow} \mathrm{i} \beta^{\wedge}+\gamma_{\downarrow}{ }_{\downarrow} 0 \lambda^{\wedge} \mathrm{i}\right)$ para os grupos de famílias pluriativas, é necessário gerar termos nãoobservados $\hat{v}_{0}$, pois não se tem os resíduos para as observações das famílias pluriativas.

Segundo De Janvry et al. (2005) e Zhu e Luo (2006), para isso, se constrói uma variável aleatória

$$
\hat{v}_{0 \mathrm{i}}=\hat{\sigma}_{0} \phi^{-1}(\mathrm{r})
$$

em que $\hat{\sigma}_{0}$ é o erro padrão estimado de $v_{0 \mathrm{i}}$ (famílias agrícolas); r se refere a uma sequência de números aleatórios entre zero e 1 ; e $\phi^{-1}$ é o inverso da função de distribuição normal padronizada acumulada. Ao final, têm-se as previsões da renda caso se dediquem exclusivamente as atividades agrícolas para todas as famílias:

$$
\widehat{W}_{0 \mathrm{i}}= \begin{cases}W_{\mathrm{i}}=X_{\mathrm{i}} \widehat{\beta}+\hat{\gamma}_{0} \widehat{\lambda}_{\mathrm{i}}+\hat{v}_{0 \mathrm{i}} & \text { quando } Y_{\mathrm{i}}=0 \\ X_{\mathrm{i}} \widehat{\beta}+\hat{\gamma}_{0} \widehat{\lambda}_{\mathrm{i}}+\hat{v}_{0 \mathrm{i}} & \text { quando } Y_{\mathrm{i}}=1\end{cases}
$$

Esse procedimento deve ser repetido para obter $\widehat{W}_{1 \mathrm{i}}$, de forma que se consiga comparar a renda da família agrícola, caso fosse pluriativa.

5 A notação segue $W_{\mathrm{oi}}$ para as famílias exclusivamente agrícolas e $W_{\mathrm{li}}$ para aquelas pluriativas. 
Então, têm-se quatro valores de renda média:

a) renda média dos indivíduos exclusivamente agrícolas, considerando que participem apenas de atividades agrícolas (fonte zero). Esse valor já é observado $\left(\left.W_{0}\right|_{P=0}\right)$;

b) renda média dos pluriativos, caso fossem exclusivamente agrícolas (fonte 0). Esta renda é simulada $\left(\left.E \hat{W}_{0}\right|_{P=1}\right)$;

c) renda média dos indivíduos exclusivamente agrícolas, considerando que fossem pluriativos (fonte 1). Esse valor também é simulado $\left(\left.E \hat{W}_{0}\right|_{P=0}\right)$; d) renda média dos pluriativos, considerando que participam de atividades agrícolas e não-agrícolas. Esse valor já é observado $\left(\left.W_{1}\right|_{P=1}\right)$.

A partir desses valores, é possível compará-los e observar o comportamento da renda dos pluriativos, caso fossem exclusivamente agrícolas $\left(\left.E \hat{W}_{0}\right|_{P=1}\right)$, frente a dos efetivamente agrícolas $\left(\left.W_{0}\right|_{P=0}\right)$. Se $\left.E \hat{W}_{0}\right|_{P=1}<\left.W_{0}\right|_{P=0}$, isso significa que os indivíduos exclusivamente agrícolas são efetivamente mais produtivos. A comparação horizontal, ou seja, entre $\left.W_{0}\right|_{P=0}$ e $\left.E \hat{W}_{1}\right|_{P=0}$ demonstra qual o prêmio para os agrícolas, caso decidam diversificar suas atividades.

Caso $\left.E \hat{W}_{0}\right|_{P=1}<\left.W_{1}\right|_{P=1}$, se pode considerar que a pluriatividade gera efeitos positivos para a própria produção agropecuária, já que contribui para relaxar a restrição imposta ao setor pela falta de um programa de seguro agrícola eficiente, além de crédito a taxas de juros e carência compatíveis com a capacidade de pagamento dos agricultores (DE JANVRY et al., 2005).

Ainda da comparação da renda com e sem a presença de atividades não-agrícolas, dentre classes decompostas pelo índice de Foster-GreerThorbecke (FGT) (FOSTER et al., 1984), se estuda o impacto do nãoagrícola sobre a pobreza. Espera-se que os índices de pobreza reduzam quando a família possui renda não-agrícola e aumentem, se as famílias forem exclusivamente agrícolas.

Fazem parte da classe de índices FGT, a Proporção de pobres $\left(\mathrm{P}_{0}\right)$, o Hiato da Pobreza $\left(\mathrm{P}_{1}\right)$ e o Hiato da Pobreza ao quadrado $\left(\mathrm{P}_{2}\right)$. O índice Proporção de Pobres mede a proporção de famílias que possuem renda per capita familiar não superior a linha de pobreza. Esse indicador é importante, mas possui limitações ${ }^{6}$ e por isso não deve ser considerado isolado. $\mathrm{O}$ índice Hiato da Pobreza mede a intensidade da pobreza e pode ser interpretado como um indicador do déficit de pobreza. O índice Hiato da Pobreza ao quadrado é geralmente descrito como um indicador de severidade da pobreza. Dá-se um maior peso para as pessoas mais pobres e leva-se em conta a desigualdade de renda entre os pobres. Os

6 O indicador permanece o mesmo quando a renda se eleva sem alcançar a linha da pobreza. A proporção também é insensivel à distribuição de renda entre os pobres, ou seja, permanece inalterada se houver transferência de renda entre um mais e outro menos pobre (MARIANO; NEDER, 2004). 
dois últimos índices enfatizam as famílias que estão muito abaixo da linha de pobreza pré-determinada ( $z$ ), ou seja, os mais pobres entre os pobres (MARIANO; NEDER, 2004). Esses são calculados segundo as seguintes expressões:

$$
\begin{aligned}
& P_{0}=\frac{\mathrm{q}}{\mathrm{n}} \\
& P_{1}=\frac{1}{\mathrm{n}} \sum_{\mathrm{i}=1}^{\mathrm{q}} \frac{z-\gamma_{\mathrm{i}}}{z} \\
& P_{2}=\frac{1}{\mathrm{n}} \sum_{\mathrm{i}=1}^{\mathrm{q}}\left(\frac{z-\gamma_{\mathrm{i}}}{z}\right)^{2}
\end{aligned}
$$

onde,

q é o número de pobres, ou seja, famílias com renda per capita não superior a linha de pobreza pré-determinada;

n é o tamanho da população;

$z$ é a linha da pobreza pré-determinada;

$\gamma_{i}$ é um vetor de renda per capita familiar da i-ésima família em ordem crescente.

Finalmente, partir da renda observada e da simulada obtida da regressão supracitada, se pode calcular dois índices de Gini. Este mede a desigualdade relativa da distribuição de renda pela razão entre a área da desigualdade $(\alpha)$ e a área de uma distribuição de perfeita igualdade da Curva de Lorenz. ${ }^{7}$ Dentre as diversas fórmulas existentes, a utilizada nesta pesquisa é

$$
G=\left(1+\frac{1}{n}\right)-\frac{2}{n^{2} \mu} \sum_{\mathrm{i}=1}^{n} i x_{\mathrm{i}}
$$

onde $\mu$ é a renda média; $n$ é o número de observações; e $x_{\mathrm{i}}$ são as rendas.

Caso o índice obtido dos valores observados, que incluem as rendas não-agrícolas, seja maior do que o simulado (sem a renda não-agrícola), isso significa que a presença da renda não-agrícola concentra renda. Os erros-padrões, viés e intervalo de confiança dos índices são obtidos pelo método de reamostragem bootstrap. Segundo Chernick (1999), bootstrap é frequentemente usado quando é muito difícil calcular a estimativa do erro padrão de um estimador. Sua vantagem frente ao método de Monte Carlo é que não é necessário conhecer o processo gerador dos dados para ser utilizado.

$7 \quad \mathrm{G}=\frac{\alpha}{0,5}=2 \alpha$, como $0 \leq \alpha \leq 0,5$, tem-se que o índice de Gini varia entre 0 e 1. 


\subsection{Modelo Empírico e Fonte de Dados}

Foram estimados dois modelos Tobit II, por máxima pseudo-verossimilhança. No primeiro, busca-se estimar a renda média das familias pluriativas e simular a renda das famílias agrícolas, caso fossem exclusivamente pluriativas. No segundo modelo, se faz o inverso, ou seja, pretende-se estimar a renda média das famílias agrícolas e simular a renda das famílias pluriativas, se fossem agrícolas. As variáveis dependentes das equações de seleção são dummies que, no primeiro caso, assume valor 0 se a família for agrícola e 1 , se for pluriativa. O inverso ocorre no segundo caso. Para a equação que estima a renda média, a variável dependente é contínua e censurada contendo ou as informações das famílias agrícolas ou das famílias pluriativas. As variáveis explicativas são as mesmas nos dois modelos, tanto para a equação de seleção quanto a que estima a renda média. Na equação de seleção, as variáveis utilizadas são idade média da PEA restrita ${ }^{8}$ (idpeares); e idade média da PEA restrita ao quadrado (idpeares2); média de anos de estudo (anoest); número de componentes da família (numcompfam1); posição na ocupação, definida como 1 para empregador, 2 para conta-própria, 3 se for empregado, 4 no caso dos não-ocupados (vposocup); local de moradia, que assume valores de 1 a 5 , sendo 1 o rural mais próximo do urbano e 50 rural mais distante, com os demais valores estando ordenados pelo local de moradia da família; razão de dependência é formada dividindo o número de membros da família considerados dependentes pela idade da PEA ativa (razaodep); e uma variável dummy indicando se a família possui ou não renda do não-trabalho, como aposentadorias, pensões ou transferência de renda do governo, por exemplo (rendant). Praticamente as mesmas variáveis foram utilizadas para estimar a renda média, sendo retirado apenas idpeares2 para melhorar a qualidade do ajustamento do modelo.

Os dados foram obtidos através da PNAD/IBGE para o ano de 2005 e se referem aos três estados da região Sul (Paraná, Santa Catarina e Rio Grande do Sul). Nas estimações, incorpora-se o delineamento amostral da PNAD, seus pesos, estratos e PSU (unidade primária amostral). Como a PNAD não é IID (Independente e Identicamente Distribuída), ou seja, como não se origina de uma amostra aleatória simples com reposição e sim de uma amostragem complexa, ${ }^{9}$ a não consideração do plano amostral faz com que as estimações pontuais estejam incorretas e as variâncias calculadas erroneamente (PESSOA \& NASCIMENTO SILVA, 1998). Para obter mais precisão, faz-se necessário considerar o plano amostral. As

8 PEA restrita se refere as pessoas com 10 anos ou mais que trabalharam que trabalharam mais de 15 horas na semana de referência , excluídas as que se dedicam apenas ao autoconsumo.

9 A PNAD possui estratificação, conglomerados e probabilidades desiguais de seleção (GUIMARÃES, 2007) 
variâncias calculadas nas equações de regressão são obtidas pelo método de Linearização de Taylor. Este método tem como princípio a aproximação de estimadores não-lineares de interesse por estimadores lineares para calcular a variância dessa aproximação e usar como proxy para a variância do estimador não-linear. Para os cálculos de erros-padrões e intervalos de confiança dos índices, utiliza-se tanto o método de Linearização de Taylor quanto o Bootstrap, comparando-os. Para a definição da linha de pobreza, segue-se o mesmo procedimento adotado por Nascimento (2005) e Guimarães (2007), considerando meio salário mínimo do período de referência $(\mathrm{R} \$ 150,00$ para 2005). O software utilizado é o Stata 10 da StataCorp LP, com o uso das rotinas ineqerr, suylorenz, poudeco e sepou.

\section{Discussão dos Resultados}

\subsection{Caso das Familias Agrícolas, se Fossem Pluriativas}

Dentre outras variáveis, a Tabela 1 apresenta a média, erro padrão e o intervalo de confiança para a renda das famílias agrícolas (renagr) e renda das famílias pluriativas (renplur). O número de observações (1.160) ponderado pelo peso representa um total de aproximadamente $650 \mathrm{mil}$ famílias exclusivamente agrícolas no meio rural da região Sul. Com relação às pluriativas, a expansão para a população indica estar-se trabalhando com um total de aproximadamente 300 mil famílias pluriativas, ou seja, pouco menos da metade das famílias agrícolas. A renda média das famílias pluriativas $(R \$ 1.354,18)$, por outro lado, é superior a renda média das famílias agrícolas ( $\mathrm{R} \$ 937,43)$, indicando que a renda das famílias agrícolas compreende, aproximadamente, $70 \%$ da renda das pluriativas. Chama ainda a atenção que, na média, a quantidade de anos de estudo média das familias é de aproximadamente 5 anos e a idade média da PEA restrita está em torno dos 34 anos. A maior parte das famílias recebe algum tipo de renda do não-trabalho e a grande maioria reside no rural denominado nos estudos do projeto Rurbano de "agropecuário", ou seja, o rural mais distante do urbano possível.

Tabela 1 - Média das variáveis, considerando o plano amostral

\begin{tabular}{c|c|c|c|c|c}
\hline Variável & $\begin{array}{c}\text { Número de } \\
\text { observações }\end{array}$ & Média & $\begin{array}{c}\text { Erro-padrão } \\
\text { linearizado }\end{array}$ & \multicolumn{2}{|c}{$\begin{array}{c}\text { Intervalo de confiança } \\
\text { (95\%) }\end{array}$} \\
\hline renagr & 1.160 & 967,43 & 44,713 & 848,30 & $1.026,57$ \\
\hline renplur & 557 & $1.354,18$ & 77,22 & $1.200,24$ & $1.508,11$ \\
\hline idpeares & 1.717 & 34,22 & 0,32 & 33,59 & 34,86 \\
\hline anosest & 1.717 & 4,98 & 0,084 & 4,81 & 5,15 \\
\hline
\end{tabular}

LIMA, J. R. F.; PIACENTI, C. A. O papel das rendas não-agrícolas para redução da pobreza... 
(continuação)

\begin{tabular}{c|l|l|l|l|l}
\hline numcompfam & 1.717 & 3,53 & 0,038 & 3,45 & 3,61 \\
\hline rendant & 1.717 & 0,54 & 0,018 & 0,51 & 0,58 \\
\hline vposocup & 1.717 & 2,25 & 0,029 & 2,20 & 2,31 \\
\hline localmora & 1.717 & 4,97 & 0,015 & 4,94 & 5,01 \\
\hline razaodep & 1.717 & 0,40 & 0,012 & 0,38 & 0,43 \\
\hline
\end{tabular}

Fonte: Dados reprocessados da PNAD (2005), pelos autores.

Pode-se, inicialmente, para entender melhor a renda observada das famílias agrícolas e sua renda simulada, caso fossem pluriativas, analisar a estimativa não-paramétrica de função de densidade utilizando o estimador Kernel e compará-lo com a distribuição Normal (a qual possui as características de ser simétrica e mesocúrtica). A Figura 1 representa essas distribuições com o logaritmo da renda observada. Percebe-se uma "cauda" bem mais pesada na parte inferior a média (centro da distribuição), indicando a existência de uma grande quantidade de famílias com renda menor (e bastante menor) do que a média das famílias agrícolas, possivelmente demonstrando a pobreza existente nesse tipo de família. Outra característica interessante da função Kernel, comparada com a distribuição Normal, é que a primeira é bem mais leptocúrtica, ou seja, próximo à média da distribuição existe uma maior concentração de observações, provavelmente indicando uma maior concentração da renda. O "pico" da função Kernel está próximo de 0,5, enquanto o da distribuição Normal é inferior a 0,4.

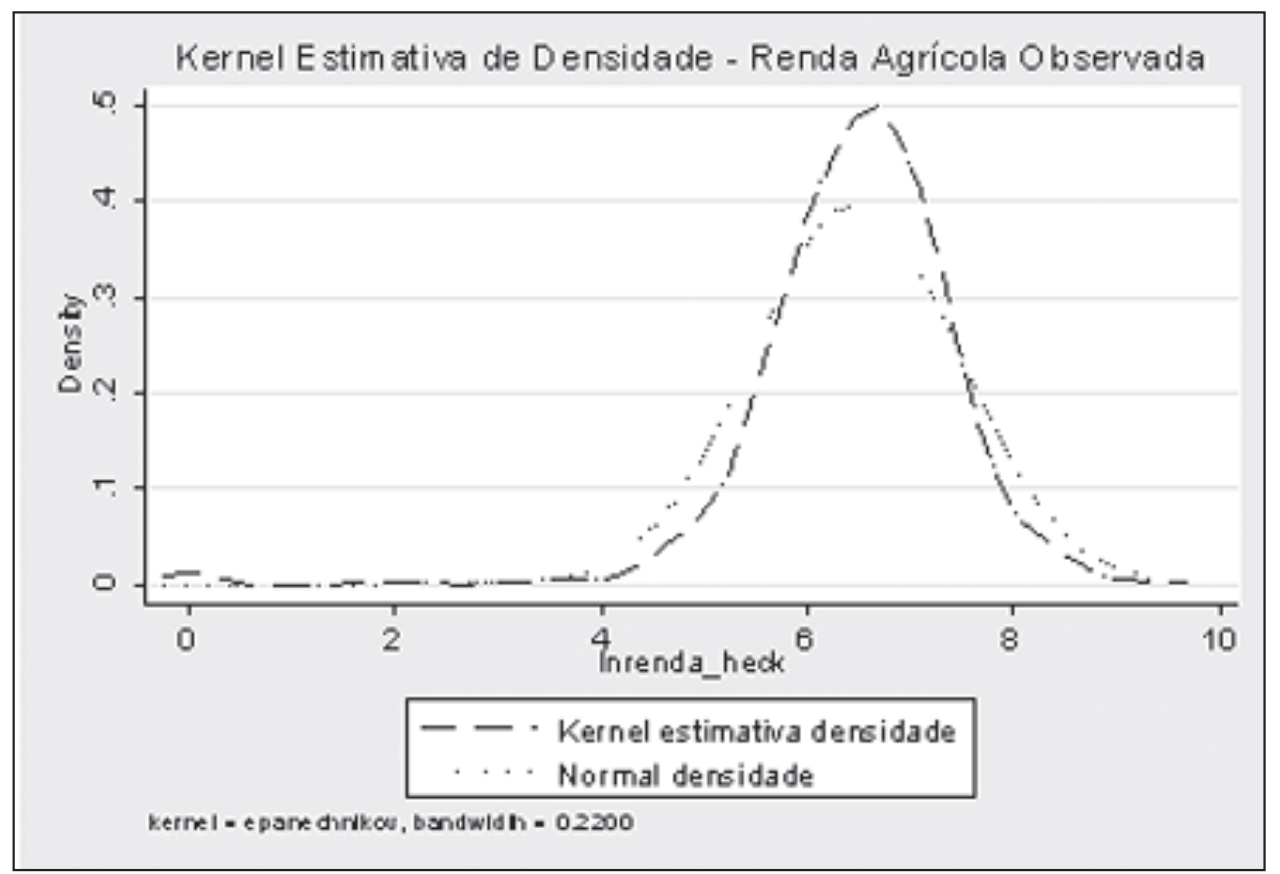

Figura 1 - Função Kernel para o logaritmo da renda observada das famílias agrícolas da região Sul - Ano de 2005

Fonte: Dados da Pesquisa. 
A Figura 2 representa também a estimativa não-paramétrica de função de densidade utilizando o estimador Kernel e a comparação com a distribuição Normal, agora para o logaritmo da renda simulada das famílias agrícolas, ou seja, caso fossem pluriativas. As duas distribuições estão praticamente sobrepostas, sem "cauda" longa na parte inferior à média, demonstrando que a renda não-agrícola possivelmente contribui tanto para redução da pobreza quanto da concentração de renda no meio rural da região Sul.

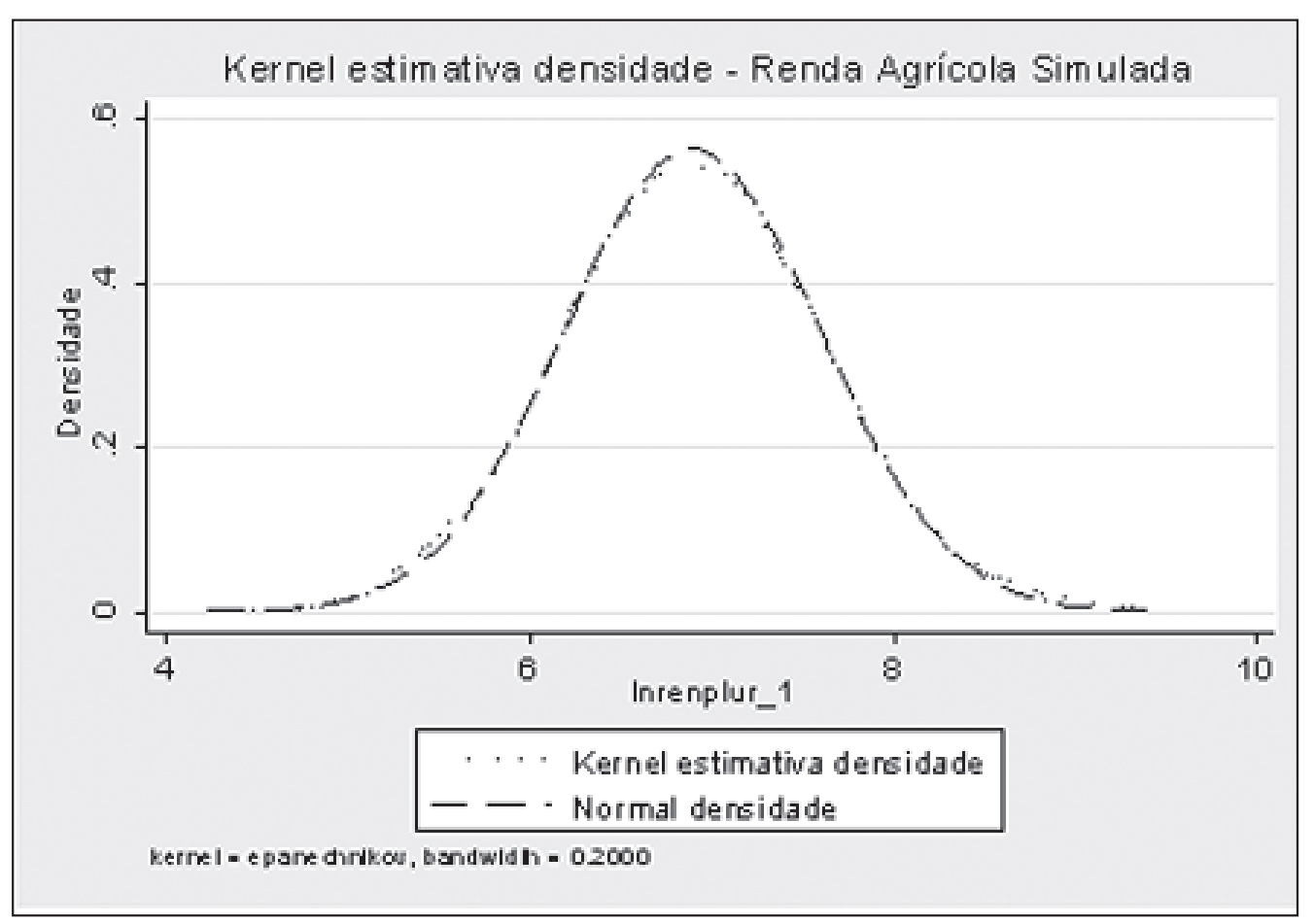

Figura 2 - Função Kernel para o logaritmo da renda simulada das famílias agrícolas, caso fossem pluriativas, da região Sul - Ano de 2005

Fonte: Dados da Pesquisa.

A Tabela 2 reporta os valores estimados dos índices de pobreza FGT, a proporção de pobres $\left(\mathrm{P}_{0}\right)$, o hiato da pobreza $\left(\mathrm{P}_{1}\right)$ e o hiato da pobreza ao quadrado/severidade da pobreza $\left(\mathrm{P}_{2}\right)$ tanto para o caso do logaritmo da renda observada das famílias agrícolas, quanto para a renda simulada. Manteve-se a renda em logaritmo simplesmente porque não se está interessado no valor em si do índice. O interesse é saber se o mesmo é maior ou menor, comparando valores observados e simulados. Como indicado, tanto para a proporção de pobres, quanto para o hiato da pobreza e a severidade da pobreza, os valores se reduzem bastante no caso das famílias agrícolas, se fossem pluriativas. Apesar da forte redução na proporção de pobres e no hiato da pobreza, é importante observar que praticamente não se teria mais famílias em situação de pobreza severa, ou seja, os mais pobres dos pobres. 
A coluna que demonstra os cálculos do MEFF (Misspecification effect) ${ }^{10}$ é importante para demonstrar que a não caracterização do plano amostral subestima a variância no caso da renda observada (principalmente em $\mathrm{P}_{1}$ e $\mathrm{P}_{2}$ ) e superestima a mesma, no caso da renda simulada.

Tabela 2 - Medidas de índices de pobreza (FGT) para rendas das famílias agrícolas: observada e simulada, caso fossem pluriativas.

Renda logaritmizada. Região Sul - 2005

\begin{tabular}{|c|c|c|c|c|c|}
\hline & Estimativa(\%) & Erro-padrão & \multicolumn{2}{|c|}{ Intervalo de confiança (95\%) } & MEFF \\
\hline \multicolumn{6}{|c|}{ Renda observada } \\
\hline $\mathrm{P}_{0}$ & 3,63881 & 0,0063872 & 0,023655 & 0,0491207 & 1,268027 \\
\hline $\mathrm{P}_{1}$ & 1,14415 & 0,0038122 & 0,003842 & 0,0190409 & 1,827520 \\
\hline $\mathrm{P}_{2}$ & 0,90722 & 0,0038089 & 0,0014794 & 0,0166651 & 1,941883 \\
\hline \multicolumn{6}{|c|}{ Renda simulada } \\
\hline $\mathrm{P}_{0}$ & 0,06154 & 0,0006195 & $-0,0006195$ & 0,0018503 & 0,5163733 \\
\hline$P_{1}$ & 0,00708 & 0,0000713 & $-0,0000713$ & 0,0002129 & 0,5163733 \\
\hline $\mathrm{P}_{2}$ & 0,00081 & 0,0000082 & $-0,0000082$ & 0,0000245 & 0,5163733 \\
\hline
\end{tabular}

Fonte: Dados da Pesquisa.

A Tabela 3 se refere aos índices de concentração de Gini e de entropia de Theil para a renda observada das famílias agrícolas e a simulada, se fossem pluriativas, com os erros padrões obtidos por bootstrap. A comparação entre esses demonstra valores maiores, ou seja, maior concentração, no caso da renda observada.

Tabela 3 - Medidas de índices de concentração (Gini e Theil) para as rendas das familias agrícolas: observada e simulada, caso fossem pluriativas.

Renda logaritmizada. Erros-padrões obtidos por bootstrap com 200 replicações. Região Sul - 2005

\begin{tabular}{c|c|c|c|c|c}
\hline Índice & Estimativa & Viés & Erro-padrão & $\begin{array}{c}\text { Intervalo de confiança } \\
\text { com correção de viés (95\%) }\end{array}$ \\
\hline \multicolumn{5}{l|}{ Renda observada } \\
\hline Gini & 0,0766084 & $-0,0003655$ & 0,0048196 & 0,0687638 & 0,0888056 \\
\hline Theil & 0,0165285 & 0,0001244 & 0,004734 & 0,0090897 & 0,0275847 \\
\hline
\end{tabular}

10 Razão entre a variância do parâmetro considerando o plano amostral complexo e a variância baseada na hipótese incorreta de que as observações foram obtidas por amostragem aleatória simples com reposição, ou seja, são estimadores obtidos simplesmente ignorando pesos, estratificação e conglomeração. Se MEFF > 1, a variância desconsiderando o plano amostral está subestimada. Se MEFF for $<1$, a variância desconsiderando o efeito do plano amostral está superestimada. Se MEFF = 1, não há diferença entre as variâncias. 
Renda simulada

\begin{tabular}{c|c|c|c|c|c}
\hline Gini & 0,0577372 & 0,0001649 & 0,001759 & 0,054445 & 0,0604453 \\
\hline Theil & 0,0052772 & 0,0000328 & 0,0003181 & 0,0046727 & 0,0057584 \\
\hline
\end{tabular}

Fonte: Dados da Pesquisa.

Se as famílias agrícolas tivessem renda não-agrícola, haveria redução da desigualdade de renda no meio rural da região Sul. No caso do índice de Gini, é possível comparar os valores da Tabela 3 e da Tabela 4 e observar que existe uma pequena diferença nos valores calculados e que os erros-padrões calculados por linearização de Taylor são ligeiramente menores do que aqueles calculados por bootstrap.

Tabela 4 - Medidas de índices de concentração (Gini) para as rendas das famílias agrícolas: observada e simulada, caso fossem pluriativas.

Renda logaritmizada. Erros-padrões obtidos por Linearização de Taylor.

Região Sul - 2005

\begin{tabular}{c|c|c|c|c|c}
\hline Índice & Estimativa & Erro-Padrão & P-Valor & Intervalo de Confiança (95\%) \\
\hline \multicolumn{5}{l|}{ Renda Observada } \\
\hline Gini & 0,0759497 & 0,00412231 & 0,000 & 0,0678701 & 0,0840293 \\
\hline \multicolumn{7}{l}{ Renda Simulada } \\
\hline Gini & 0,0578380 & 0,00146305 & 0,000 & 0,0549704 & 0,0607055 \\
\hline
\end{tabular}

Fonte: Dados da Pesquisa.

\subsection{Caso das Familias Pluriativas, se Fossem Agrícolas}

Como o tópico anterior buscou caracterizar, a renda não-agrícola contribui para redução da pobreza e da desigualdade no meio rural da região Sul. As rendas simuladas das famílias agrícolas, quando comparadas com as observadas, indicam redução nos indicadores de pobreza e de concentração. Neste tópico, a análise será invertida. Novamente se estimará uma equação que explica a decisão da família e depois uma para a renda média. A diferença é que a renda média será da família agrícola e a simulação será para as famílias pluriativas, caso fossem agrícolas.

Da mesma forma, para entender melhor a renda observada e a simulada para as famílias pluriativas, analisa-se a estimativa não-paramétrica de função de densidade utilizando o estimador Kernel e compara-o com a distribuição Normal (Figura 3). Percebe-se uma "cauda" ligeiramente mais pesada na parte superior à média (centro da distribuição), indicando a existência de uma maior quantidade de famílias com renda superior a média das famílias pluriativas, algo positivo. 


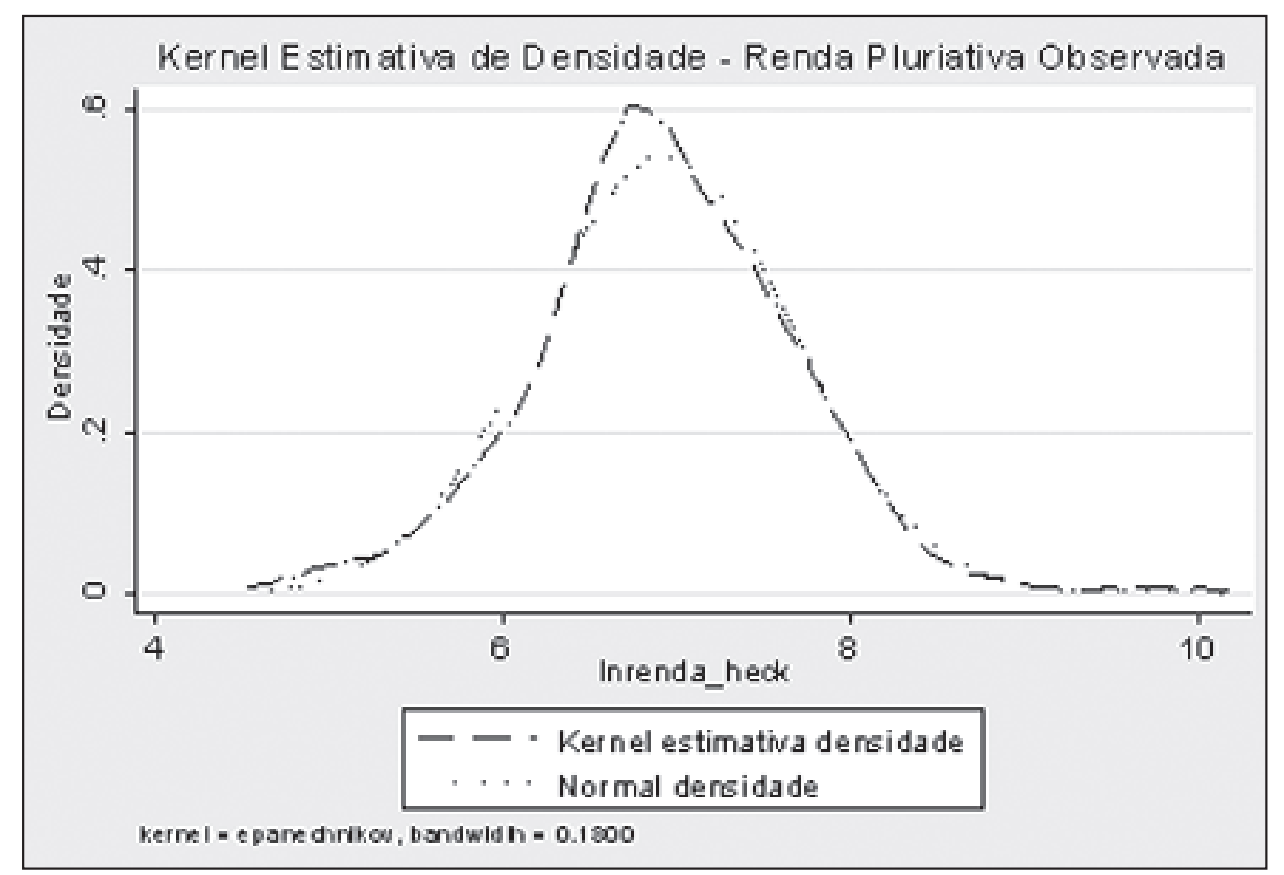

Figura 3 - Função Kernel para o logaritmo da renda observada das famílias pluriativas da região Sul - Ano de 2005

Fonte: Dados da Pesquisa.

Comparada com a distribuição Normal, percebe-se que a Kernel possui um "bico" ligeiramente mais elevado (mais pontiaguda), mas não apresenta

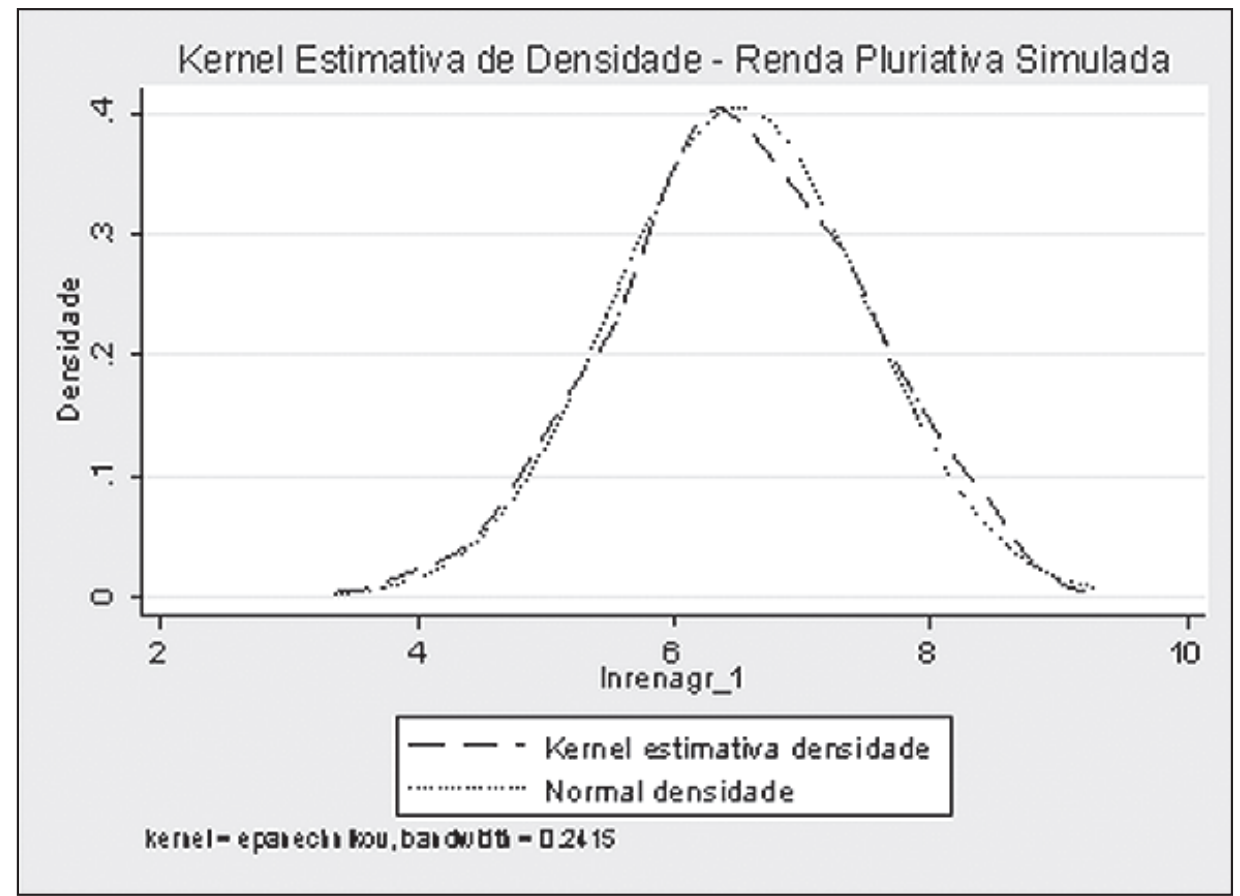

Figura 4 - Função Kernel para o logaritmo da renda simulada das famílias pluriativas caso fossem agrícolas. Região Sul - Ano de 2005

Fonte: Dados da Pesquisa. 
uma grande concentração mais próxima da média, se assemelhando mais a uma curva positivamente assimétrica.

A Figura 4 representa a função Kernel e a normal do logaritmo da renda simulada das famílias pluriativas caso fossem agrícolas. Aparentemente, as duas distribuições são semelhantes com relação à curtose, sem "caudas" pesadas. Diferem na média, sendo que o centro da Kernel está mais a esquerda do que a normal, ou seja, possui média (do log da renda) menor.

A Tabela 5 se refere aos índices FGT para as rendas das familias pluriativas. Os três índices de pobreza, quando considerada a renda observada, apresentam valores menores comparativamente aos valores obtidos com a renda simulada, ou seja, se as famílias pluriativas não tivessem a renda não-agrícola. Por exemplo, haveria um substancial aumento na proporção de pobres, que passaria de $0,91 \%$ para cerca de $7 \%$. Isso reforça a importância da renda não-agrícola para redução da pobreza.

Tabela 5 - Medidas de índices de pobreza (FGT) para rendas das famílias pluriativas: observada e simulada, caso fossem agrícolas.

Renda logaritmizada. Região Sul - 2005

\begin{tabular}{|c|c|c|c|c|c|}
\hline & Estimativa (\%) & Erro-Padrão & \multicolumn{2}{|c|}{ Intervalo de Confiança (95\%) } & MEFF \\
\hline \multicolumn{6}{|c|}{ Renda Observada } \\
\hline $\mathrm{P}_{0}$ & 0,9148 & 0,0039081 & 0,0013574 & 0,0169386 & 0,9545505 \\
\hline $\mathrm{P}_{1}$ & 0,03037 & 0,0001516 & 0,0000014 & 0,0006059 & 0,9536601 \\
\hline $\mathrm{P}_{2}$ & 0,00134 & 0,0000082 & $-0,0000029$ & 0,0000297 & 1,017885 \\
\hline \multicolumn{6}{|c|}{ Renda Simulada } \\
\hline $\mathrm{P}_{0}$ & 6,99476 & 0,010381 & 0,0492534 & 0,0906418 & 0,9201798 \\
\hline $\mathrm{P}_{1}$ & 0,55112 & 0,0009224 & 0,0036725 & 0,00735 & 0,5754661 \\
\hline $\mathrm{P}_{2}$ & 0,07874 & 0,0001789 & 0,0004308 & 0,0011439 & 0,5148265 \\
\hline
\end{tabular}

Fonte: Dados da Pesquisa.

A Tabela 6 trata dos índices de Gini e Theil considerando a renda das familias pluriativas observada e simulada. Com esses valores fica mais clara a identificação da importância da renda não-agrícola para redução da concentração de renda. Tanto para o Gini quanto para o Theil calculado, os valores são maiores para o logaritmo da renda simulada comparando com o log da renda observada.

Para o índice de Gini, é possível comparar os valores da Tabela 6 e da Tabela 7 e observar que, semelhante ao que ocorre no item anterior, os erros-padrões calculados por linearização de Taylor são ligeiramente menores do que aqueles calculados por bootstrap. 
Tabela 6 - Medidas de índices de concentração (Gini e Theil) para as rendas das famílias pluriativas: observada e simulada, caso fossem agrícolas.

Renda logaritmizada.Erros-padrões obtidos por bootstrap com 200 replicações. Região Sul - 2005

\begin{tabular}{|c|c|c|c|c|c|}
\hline Índice & Estimativa & Viés & Erro-Padrão & \multicolumn{2}{|c|}{$\begin{array}{c}\text { Intervalo de Confiança } \\
\text { com correção de viés (95\%) }\end{array}$} \\
\hline \multicolumn{6}{|c|}{ Renda Observada } \\
\hline Gini & 0,0586448 & $-0,0002516$ & 0,002927 & 0,0537364 & 0,0643009 \\
\hline Theil & 0,005648 & $-0,000045$ & 0,0005783 & 0,0046588 & 0,0068501 \\
\hline \multicolumn{6}{|c|}{ Renda Simulada } \\
\hline Gini & 0,0855921 & 0,0000485 & 0,0029989 & 0,0784576 & 0,0909249 \\
\hline Theil & 0,011588 & 0,0000002 & 0,000789 & 0,0097738 & 0,0130994 \\
\hline
\end{tabular}

Fonte: Dados da Pesquisa.

Tabela 7 - Medidas de índices de concentração (Gini) para as rendas das famílias pluriativas: observada e simulada, caso fossem agrícolas.

Renda logaritmizada. Erros-padrões obtidos por Linearização de Taylor.

Região Sul - 2005

\begin{tabular}{c|c|c|c|c|c}
\hline Índice & Estimativa & Erro-Padrão & P-Valor & Intervalo de Confiança (95\%) \\
\hline Renda Observada \\
\hline Gini & 0,0590264 & 0,0028192 & 0,000 & 0,0535009 & 0,064552 \\
\hline \multicolumn{5}{l}{ Renda Simulada } \\
\hline Gini & 0,0858321 & 0,00260483 & 0,000 & 0,0807268 & 0,0909375 \\
\hline
\end{tabular}

Fonte: Dados da Pesquisa.

\subsection{Efeitos Positivos da Renda Não-agrícola para a Atividade Agropecuária}

A Tabela 8 reporta as rendas observadas e simuladas das famílias agrícolas e pluriativas. De forma semelhante ao raciocínio desenvolvido por De Janvry et al.(2005), a comparação dos resultados da Tabela 8 permite a derivação de duas conclusões. A primeira é que se os pluriativos fossem exclusivamente agrícolas, teriam renda média $(R \$ 1075,06)$ superior à renda dos exclusivamente agrícolas ( $\mathrm{R} \$ 937,43)$. Isso significa que as atuais famílias exclusivamente agrícolas da região Sul não são as mais eficientes economicamente. Consequentemente, pode-se esperar uma redução do número de famílias exclusivamente agrícolas e uma elevação do número de pluriativas ou até mesmo de exclusivamente não-agrícolas.

Segundo Nascimento (2007), esse processo já é observado na região:

[...] no Sul, os dados indicam um processo contínuo de proletarização completa dos produtores familiares que se convertem, ano a ano, de famílias de 
conta própria agrícolas e pluriativas em famílias não-agrícolas - por conta própria ou assalariamento (NASCIMENTO, 2007, p. 655).

Com relação às familias pluriativas, pode-se considerar que são os mais eficientes, pois sua renda média observada $(R \$ 1354,18)$ é superior a renda das famílias agrícolas, se fossem pluriativas $(\mathrm{R} \$ 1281,59)$.

Tabela 8 - Renda média dos dois tipos de famílias em cada fonte.

Região Sul - 2005

\begin{tabular}{c|c|c}
\hline Tipos de Famílias & Fonte 0 - Agrícolas $\left(\mathrm{W}_{0}\right)$ & Fonte $1-$ Pluriatividade $\left(\mathrm{W}_{1}\right)$ \\
\hline Famílias Agrícolas $(\mathrm{P}=0)$ & $\left.\mathrm{W}_{0}\right|_{P=0}=937,43$ & $\left.E \hat{\mathrm{W}}_{1}\right|_{P=0}=1281,59$ \\
\hline Famílias Pluriativas $(\mathrm{P}=1)$ & $\left.E \hat{\mathrm{W}}_{0}\right|_{P=1}=1075,06$ & $\left.\mathrm{~W}_{1}\right|_{P=1}=1354,18$ \\
\hline
\end{tabular}

Fonte: Dados da Pesquisa.

A segunda conclusão é que as rendas não-agrícolas criam efeitos positivos para a atividade agropecuária. Delgado e Cardoso (2000) defendem a tese de que, em muitos casos, é uma parte da renda das aposentadorias percebidas pelos mais velhos que é utilizada como recurso para investimento produtivo no estabelecimento rural. Certamente que outras fontes provenientes de transferências privadas (um parente que migrou, por exemplo) ou de atividades não-agrícolas, como do trabalho de alguma filha ou filho numa cidade próxima, ajudam as famílias a se manter no estabelecimento e podem até servir para aquisição do necessário para a preparação do solo, plantio ou colheita agrícola. A dificuldade do acesso ao crédito, o risco da tomada do mesmo e/ou taxas de juros incompatíveis com a capacidade de pagamento dos produtores, podem dificultar a atividade agropecuária. Por outro lado, a renda não-agrícola pode relaxar essa restrição.

Como pode ser observado na Tabela 8, para as famílias pluriativas a renda não-agrícola contribui para a elevação da renda da família em cerca de $26 \%(\mathrm{R} \$ 1075,06$ para $\mathrm{R} \$ 1354,18)$. Para as exclusivamente agrícolas, se fossem famílias pluriativas o ganho na renda seria de aproximadamente $37 \%(\mathrm{R} \$ 937,43$ para $\mathrm{R} \$ 1281,59)$. Como cita De Janvry et al. (2005, p. 16):

[...] hence, participation i non-farm activities helps raise total factor productivity in agriculture, expectedly by helping relax the constraints on agriculture imposed by the pervasive credit and insurance market failures that characterize a transition economy. 


\section{Considerações Finais}

O trabalho demonstra a importância da renda não-agrícola para redução da pobreza rural e da concentração, na região Sul do Brasil. Apesar de existir na região um número de famílias exclusivamente agrícolas maior do que o total das pluriativas, as primeiras percebem apenas 70\% da renda total das que possuem parcela não-agrícola.

As simulações demonstraram que se as famílias agrícolas fossem pluriativas, poderiam elevar seus rendimentos, o que contribuiria para redução dos índices de pobreza FGT, principalmente no caso da pobreza severa. A concentração também seria reduzida, como indica a estimativa do índice de Gini e Theil.

A situação se inverte quando se simula a renda das famílias pluriativas, se fossem exclusivamente agrícolas. A renda média familiar se reduziria, aumentando bastante a proporção de pobres e os demais índices FGT. A concentração também se elevaria. Uma explicação plausível para a elevação da concentração causada pela renda agrícola, é que essa possui uma relação com a posse das terras, a qual é concentrada. Por outro lado, não existe este link entre a renda não-agrícola e a propriedade das terras, sendo mais relevante para os mais pobres.

O aumento do número de famílias pluriativas e não-agrícolas, com redução da quantidade de famílias agrícolas deve continuar ocorrendo, pois essas não são as mais eficientes economicamente. Se as famílias pluriativas fossem exclusivamente agrícolas, perceberiam uma renda maior do que a das atuais famílias agrícolas.

A renda não-agrícola pode relaxar várias restrições, como a dificuldade do acesso ao crédito, o risco da tomada do mesmo e/ou taxas de juros incompatíveis com a capacidade de pagamento dos produtores, criando efeitos positivos para a atividade agropecuária.

\section{Referências}

ANDRADE, V. D. A. O papel do estabelecimento agrícola e das características pessoais e familiares na alocação de trabalho no meio rural brasileiro. Tese de Doutorado em Economia Aplicada - Departamento de Economia Rural, Universidade Federal de Viçosa, Minas Gerais, 2003. 136f.

CARNEIRO, M. J. Significados da pluriatividade para a família rural. In: SEMINÁRIO NACIONAL DE DESENVOLVIMENTO RURAL SUSTENTÁVEL. Texto para Discussão. Ministério do Desenvolvimento Agrário (MDA) - Conselho Nacional de Desenvolvimento Rural Sustentável (CONDRAF). Brasília, agosto de 2005. 7p.

CHERNICK, M. R. Bootstrap methods: a practitioner's guide. New York: John Wiley $\mathcal{E}$ Sons, 1999. 264p. 
DE JANVRY, A.; SADOULET, E.; ZHU, N. The Role of Non-Farm Incomes in Reducing Rural Poverty and Inequality in China. Department of Agricultural $\mathbb{E}$ Resource Economics, UCB. CUDARE Working Paper 1001, Mar. 2005. 29 p. Disponível em: < http://repositories.cdlib. org/are_ucb/1001> Acesso em: fev. 2007.

DELGADO, G.; CARDOSO JR., J. C. - Principais Resultados da Pesquisa Domiciliar sobre a Previdência Rural na Região Sul do Brasil (projeto avaliação socioeconômica da previdência social rural). Texto para discussão IPEA, Brasília: IPEA, n. 734, jun/2000. 63p.

FOSTER, J., J. GREER, THORBECKE, E. A Class of Decomposable Poverty Measures. Econométrica, v. 52, n.3, p. 761-766, May 1984.

GUIMARÃES, P. W. Variação de renda familiar, desigualdade e pobreza no Brasil. Tese de Doutorado em Economia Aplicada - Departamento de Economia Rural, Universidade Federal de Viçosa, Minas Gerais, 2007. 177f.

GRAZIANO DA SILVA, J. O novo rural brasileiro. $2^{\mathrm{a}}$ ed. rev. Campinas, SP: Editora da UNICAMP, 1999. (Coleção Pesquisas, 1). 151p.

HECKMAN, J. J. Sample Selection Bias as a Specification Error. Econométrica, v. 47, n. 1, Jan. p. 153-161, 1979.

HECKMAN, J. J.; LOCHNER, L. J.; TODD, P. E. Fifty years of Mincer earnings regressions. Bonn (Germany): IZA Discussion Paper n. 75, May 2003. 75p. Disponível em <http:// papers.ssrn.com/sol3/papers.cfm?abstract_id=412480 $>$. Acesso em $<$ jan/2008 $>$.

LEE, M. Off-farm labor supply and various related aspects of resource allocation by agricultural households. (Elektronische Dissertatonen) - Georg-August-Universität Göttingen, 1998. $125 f$. Disponível em: < http://webdoc.sub.gwdg.de/diss/1998/lee/> . Acesso em: <08/2007> .

MARIANO, J. L.; NEDER, H. D. Renda e Pobreza entre Famílias no meio Rural do Nordeste. In: CONGRESSO BRASILEIRO DE ECONOMIA E SOCIOLOGIA RURAL, 42, Cuiabá. Anais... (CD-ROM) Fortaleza, SOBER, 2004. 19p.

MATTEI, L. F. Pluriatividade e desenvolvimento rural no Estado de Santa Catarina. Tese de Doutorado em Desenvolvimento Econômico - Instituto de Economia Universidade Estadual de Campinas, Campinas, 1999. $211 \mathrm{f}$.

NASCIMENTO, C. A. Pluriatividade, pobreza rural e políticas públicas. Tese de Doutorado em Economia Aplicada - Instituto de Economia, Universidade Estadual de Campinas, Campinas-SP, 2005. 226f.

NASCIMENTO, C. A.; CARDOZO, S. A. Redes urbanas regionais e a pluriatividade das famílias rurais no Nordeste e no Sul do Brasil, 1992-1999 e 2001-2005. Revista Econômica do Nordeste, Fortaleza, v.38, n. 34, out-dez. p. 637-658, 2007.

PESSOA, D. G. C.; NASCIMENTO SILVA. P. L. Análise de dados amostrais complexos. São Paulo: Associação Brasileira de Estatística, 1998. 170p.

SCHNEIDER, S. A Pluriatividade na Agricultura Familiar. Porto Alegre, Editora da UFRGS, 2003.

SCHNEIDER, S.; RADOMSKY, G. F. W. A pluriatividade e as transformações do mercado de trabalho rural gaúcho: estudo de caso no município de Barão/RS. In: CAMPANHOLA, C. e GRAZIANO DA SILVA, J. (orgs.) O Novo rural brasileiro: rendas das famílias rurais. Brasília, EMBRAPA, 2004, p. 263-320.

LIMA, J. R. F.; PIACENTI, C. A. O papel das rendas não-agrícolas para redução da pobreza... 
SOUZA, M. Atividades não-agrícolas e desenvolvimento rural no Estado do Paraná. Tese de Doutorado em Engenharia Agrícola - Universidade Estadual de Campinas, Campinas-SP, 2000. 304f.

ZHU, N.; LUO, X. Nonfarm activity and rural income inequality: a case of study of two provinces in China. Policy Research Working Paper, Word Bank, n. 381 1, 2006. 26p.

\section{Anexos}

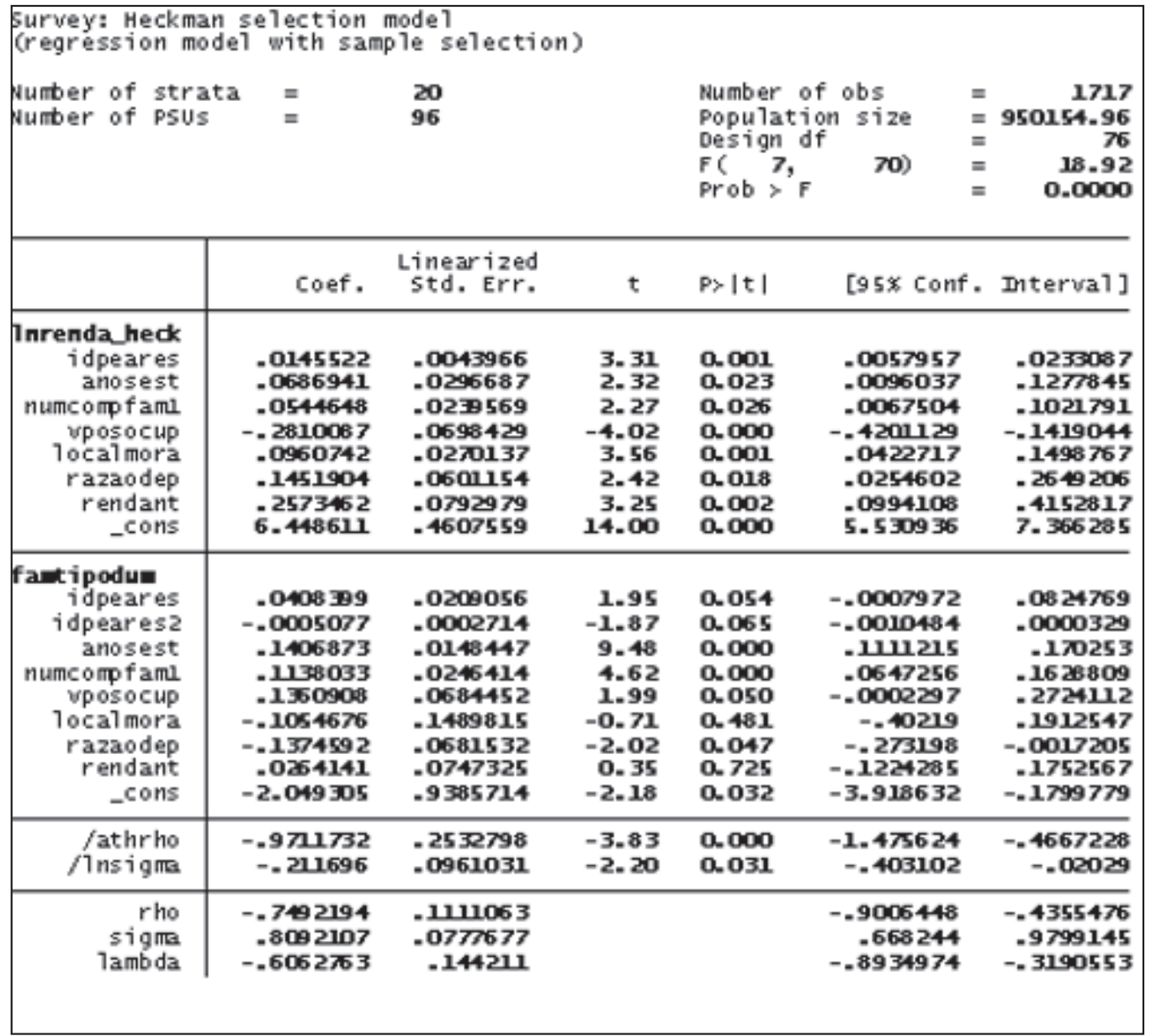




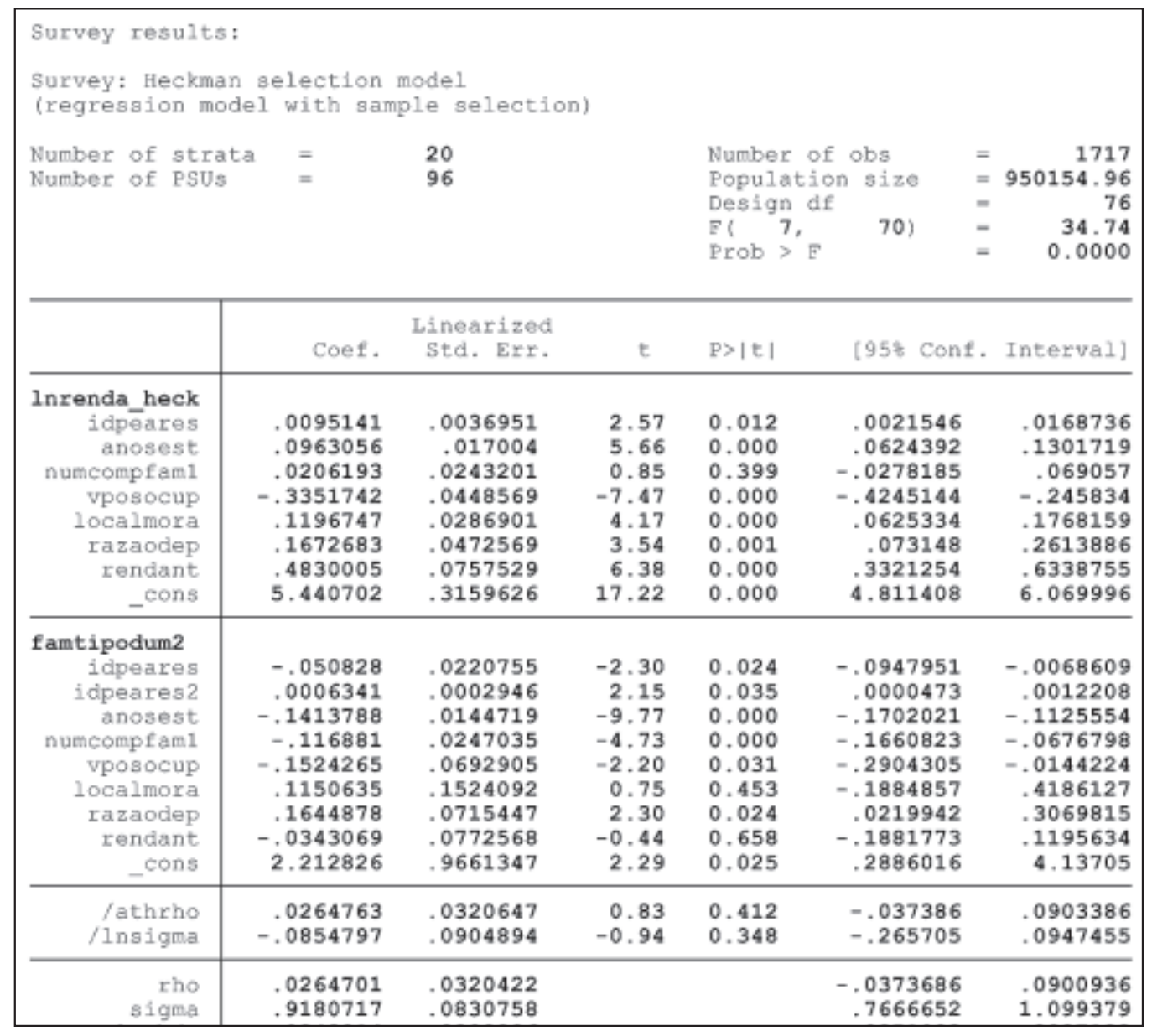

Recebido em: 07/07/2008.

Aceito em: 03/09/2008.

LIMA, J. R. F.; PIACENTI, C. A. O papel das rendas não-agrícolas para redução da pobreza... 